\title{
Hybrid sol-gel inorganic/gelatin porous fibres via solution blow spinning
}

Ryan D. Greenhalgh ${ }^{1}$, William S. Ambler ${ }^{1,2}$, Stephen J. Quinn ${ }^{1}$, Eliton S. Medeiros ${ }^{3}$, Michael Anderson ${ }^{4}$, Barbara Gore ${ }^{4}$, Angelika Menner ${ }^{5}$, Alexander Bismarck ${ }^{5}, \mathrm{Xu} \mathrm{Li}^{2}$, Nicola Tirelli ${ }^{6}$, and Jonny J. Blaker ${ }^{1, \star}$ (1)

${ }^{1}$ Bio-Active Materials Group, School of Materials, MSS Tower, The University of Manchester, Manchester M13 9PL, UK

${ }^{2}$ Institute of Materials Research and Engineering (IMRE), Agency for Science, Technology and Research (A*STAR), 2 Fusionopolis Way, Innovis, \#08-03, Singapore 138634, Singapore

${ }^{3}$ Materials and Biosystems Laboratory (LAMAB), Department of Materials Engineering (DEMat), Federal University of Paraíba (UFPB), João Pessoa, PB CEP 58051-900, Brazil

${ }^{4}$ School of Chemistry, The University of Manchester, Brunswick Street, Manchester M13 9PL, UK

${ }^{5}$ Polymer and Composite Engineering (PaCE) Group, Institute of Materials Chemistry and Research, Faculty of Chemistry, University of Vienna, Währingerstr 42, 1090 Vienna, Austria

${ }^{6}$ Division of Pharmacy and Optometry, School of Health Sciences, Stopford Building, The University of Manchester, Oxford Road, Manchester M13 9PT, UK

Received: 15 October 2016 Accepted: 31 January 2017 Published online:

8 March 2017

(C) The Author(s) 2017. This article is published with open access at Springerlink.com

\begin{abstract}
Hybrid sol-gel inorganic-organic fibres offer great potential in tissue engineering and regenerative medicine. A significant challenge is to process them using scalable technologies into useful scaffolds that provide control over fibre diameter, morphology, mechanical properties, ion release, degradation and cell response. In this work we develop formulations that are amenable to processing via solution blow spinning (SBS), a rapid technique using simple equipment to spray nano-/ micro-fibres without any electric fields. The technique is extended to produce porous class I and II hybrid fibres using cryogenic SBS, with formulations developed based on tetraethyl orthosilicate/gelatin that are relatively facile to lyophilise. The formulations developed here take advantage of the reversible thermally activated conformation change of gelatin in aqueous solutions from random coil to triple helix to enable viscosity tuning and therefore fibre spinning. Gelatin is functionalised with (3-glycidyloxypropyl)trimethoxysilane to produce class II hybrids which exhibit controllable time- and temperature-dependent viscosity profiles which can be tuned for spinning into highly porous fibres.
\end{abstract}

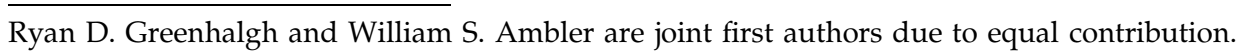

Address correspondence to E-mail: jonny.blaker@manchester.ac.uk 


\section{Introduction}

Solution blow spinning (SBS) is gaining traction as a rapid technique to produce nano- and micro-fibres, using simple equipment with no electric fields [1-6]. The fibre networks produced typically exhibit more open inter-fibre porosity than electrospun mats [7, 8]. A range of materials have been successfully processed to fibres by SBS to date, including polymers $[2,3]$, composites [9, 10], ceramic fibres either by incorporating inorganic components in a matrix followed by burn-off of the organic matrix and sintering [11-13], and those derived by sol-gel precursors and subsequent calcination [14, 15]. Highly porous bioactive composite fibres have been produced by solution blow spinning poly(D,L-lactide) solutions containing nanobioactive glass particles directly into a cryogenic bath followed by lyophilisation [9]. Macroporous bioactive nanofibre networks were further created using ice as an in situ porosifier, by spraying water droplets to the same point at which fibres contact the cryogenic phase [9]. These fibres were shown to exhibit rapid formation of hydroxycarbonate apatite (HCA) and release soluble silica ions [9]; however, due to the highly porous structure they exhibited high apparent water-in-air contact angles $\sim 140^{\circ}$ [9]. Such relatively hydrophobic materials frequently require surface modification for subsequent in vitro studies, such as plasma treatment to improve their wettability $[16,17]$.

Whilst melt and flame sprayed bioactive glasses are attractive as therapeutic ion delivery vehicles [18-23] they can be challenging to process into composite fibres, especially at high weight fractions due to issues with sedimentation and increased viscosity [9]. Sol-gel derived bioactive glasses can be produced at low temperatures and formed into monolithic scaffolds in situ by direct foaming [24-27], freeze-casting [28-30], and even fibrous structures via electrospinning and air-spraying (a process analogous to SBS) [31, 32]. Notably, bioactive glasses with compositions that contain calcium and phosphate exhibit more bioactivity than pure silica based glasses [33, 34]. However, these materials can be brittle and it can be challenging to incorporate therapeutic ions into the glass network, especially when low/non-toxic materials are desired [35, 36]. Sol-gel inorganic-organic hybrids expand the range of material properties achievable and have been comprehensively reviewed by Jones [18]. Hybrids can behave as homogeneous materials and have a range of mechanical properties that can be tailored to soft tissue [18, 25, 37-39]. Their degradation rate and mechanical properties can be tuned by judicious selection of the inorganic and organic phases as well as degree of crosslinking $[18,25,38]$. Hybrids are broadly split into two classes, class I where the inorganic and organic phases are bonded by weak intermolecular interactions, such as hydrogen bonds and van der Waals forces, and class II hybrids which have covalent bonds between the inorganic and organic phases [37, 40, 41].

In 2000, Orefice et al. [32] produced sol-gel bioactive fibres using an air-spraying process containing both calcium and phosphate ions followed by sintering. The air-spraying process employed is similar to SBS process, using an air-brush as the spraying device $[32,42,43]$. The spinnability was optimised by limiting the water content to produce quasilinear chains of silica rather than a highly connected network [32]. Electrospinning has also been used to form neat silica and calcium containing silica sol-gel fibres [31]. Most methods utilise solvent evaporation to tune the rheological properties to reach a spinning window [31, 44, 45]. Increased evaporation typically leads to higher colloidal concentration, which raises the rate of network formation. As evaporation continues viscosity is raised, and past a critical point the polycondensing sol-gel will no longer spin into fibres. The electrospinning technique has been extended to inorganic-organic hybrids formulations, commonly using tetraethyl orthosilicate (TEOS) as the inorganic phase with various natural and synthetic organic phases, including PLA [46], chitosan/poly(ethylene oxide) (PEO) [47], and gelatin functionalised with (3-glycidyloxypropyl)trimethoxysilane (GPTMS) [48, 49]. GPTMS can be used to provide the inorganic network [48], as well as act as a crosslinker between inorganic and organic phases [49].

Gelatin is attractive as organic phase particularly as it is recognised and adhered to by many cell types, can impart toughening, and is relatively hydrophilic [38]. Solvents such as hexafluoroisopropanol [50], trifluoroethanol [51, 52], and acetic acid [53, 54] have been used to fabricate gelatin nanofibre scaffolds. Whilst more challenging, aqueous electrospinning of gelatin at elevated temperatures has been achieved using a heated chamber and concentrations of or up to $30-40 \mathrm{wt} \%$ [55], or alternatively using binary PBS (phosphate-buffered saline)-ethanol solutions to tune 
ionic strength and spinning at room temperature [56]. Importantly, gelatin exhibits thermoreversible properties in aqueous solutions, existing as a random coil above sol-gelation point (circa $20^{\circ} \mathrm{C}$ ) and forms triple helices below the gelation temperature [57, 58].

In the current work, the sol-gel inorganic-organic hybrid formulations are developed to enable rapid fibre formation by SBS, leveraging the capability of cryogenic SBS (cryo-SBS) [9] to form class I and II hybrid porous fibres, the thermoreversibility of gelatin in aqueous solutions is also exploited to tune the hybrid precursor solution viscosity. Porous hybrid fibres are realised using cryo-SBS, with tertbutanol (TBA) in place of ethanol in the formulations, as it facilitates thermally induced phase separation (TIPS) and is more facile to lyophilise due to its relatively high melting point and suitable vapour pressure. Porous hybrid spheres are also produced here using these formulations, which can have application as injectable systems and for cell expansion in bioreactors. The combination of hybrid processing with cryo-SBS enables porous fibres to be produced with higher inorganic contents than particulate filled polymer fibres. The silica-gelatin porous hybrid fibres produced here are inherently hydrophilic and do not require further surface treatment, and are a platform for tuning mechanical and degradation properties, as well as ion release downstream.

\section{Materials and methods}

\section{Materials}

Gelatin derived from porcine skin (Type A, gel strength $\sim 300 \mathrm{~g}$ bloom), Dulbecco's phosphate-buffered saline (PBS, pH 7.4), tetraethyl orthosilicate (TEOS, purity 98\%, reagent grade), (3-glycidyloxypropyl)trimethoxysilane (GPTMS, purity 97\%), tert-butyl alcohol (TBA, purity $\geq 99.0 \%$ ACS reagent), ethanol (EtOH, purity $\geq 99.5 \%$ ), and $\mathrm{HCl}$ (1 M standard solution) were all obtained from Sigma Aldrich, UK.

\section{Precursor preparation, fibre spinning}

Sol-gel and hybrid fibre precursor formulations for conventional SBS

For the production of neat sol-gel silica fibres a sol was prepared using formulations based on the work of Poologasundarampillai et al. [31]. Briefly, TEOS, EtOH (mutual solvent), water and $1 \mathrm{M} \mathrm{HCl}$ (acid catalyst for hydrolysis) were added in that order to a final molar ratio of 1:2:2:0.01. Typical volumes used to make all the sol-precursors are given in Table S1. The solution was mixed for $24 \mathrm{~h}$ at room temperature in a sealed $50-\mathrm{mL}$ polypropylene container (Falcon $^{\circledR}$ tube), using a roller mixer (Stuart SRT6, Bibby Scientific, USA). This solution was then transferred to a water bath and then heated to $70{ }^{\circ} \mathrm{C}$ with the lidremoved to assist evaporation, until $\sim 65 \%$ of the mass remained and a suitable viscosity for solution blow spinning (SBS) obtained, SBS is described further below. Evaporation of EtOH has been shown to increase solution viscosity by catalysing the polycondensation of the hydrolysed TEOS [31].

Sol-gel silica-gelatin class I hybrid solutions for conventional SBS were prepared in two parts. Aqueous gelatin solutions at $10 \% \mathrm{w} / \mathrm{v}$ were prepared by dissolving gelatin (typically $1 \mathrm{~g}$ gelatin in $10 \mathrm{~mL}$ deionised water) at $40{ }^{\circ} \mathrm{C}$ under magnetic stirring in a sealed container, using a temperature controlled water bath. Separately a sol was prepared as described above to give a molar ratio of 1:0.7:1.6:0.03 (TEOS:EtOH: $\mathrm{H}_{2} \mathrm{O}: \mathrm{HCl}$ ) and mixed until the solution was clear. Hybrid solutions were typically made by mixing $6 \mathrm{~mL}$ of gelatin solution to $7 \mathrm{~mL}$ silica sol in a 100-mL sealed container under continuous magnetic stirring and the $\mathrm{pH}$ adjusted to 3.6 by drop-wise addition of $1 \mathrm{M} \mathrm{HCl}$ in $50 \mu \mathrm{L}$ increments. The hybrid solution was then heated in the sealed container under continuous stirring in a water bath at $60{ }^{\circ} \mathrm{C}$. At intervals of $5 \mathrm{~min}$, samples of the stock solution were taken for solution blow spinning, in order to identify the reaction time/window to enable fibre production (determined later to be between 30 and $40 \mathrm{~min}$, discussed below) as opposed to droplet spray or blocking.

Class I and Class II hybrid fibre precursors for cryogenic SBS

The sol formulation described above was modified to enable effective freezing and lyophilisation of the hybrids fibres, by the use of tert-butyl alcohol (TBA) in place of ethanol. TBA was selected as it has a melt point of $25^{\circ} \mathrm{C}$, has been used to form silica cryogels [59], is relatively facile to lyophilise, and forms azeotropes with water and ethanol. TEOS, TBA and $1 \mathrm{M} \mathrm{HCl}$ were added in that order to give a molar 
ratio of 1:5:2.7:0.05 (TEOS:TBA: $\mathrm{H}_{2} \mathrm{O}: \mathrm{HCl}$ ), typical volumes shown in Table S1. The sol was then roller mixed as described above for $24 \mathrm{~h}$. Class I hybrid solutions were then prepared by mixing a $10 \% \mathrm{w} / \mathrm{v}$ solution of gelatin in PBS (prepared as described above) with the hydrolysed sol. Class II hybrid precursor solutions were made by functionalising gelatin (already dissolved at $10 \% \mathrm{w} / \mathrm{v}$ in PBS) by addition of GPTMS to $92 \mu \mathrm{L} \mathrm{g}^{-1}$ of gelatin, and subsequent incubation at $40{ }^{\circ} \mathrm{C}$ for $13 \mathrm{~h}$ under continuous orbital shaking (150 rpm, using a Stuart Orbital incubator SI50, Bibby Scientific Limited, UK), following a method adapted from [60]. Class I and II hybrid solutions were typically made by mixing $7.26 \mathrm{~mL}$ of the hydrolysed sol to $8 \mathrm{~mL}$ of the gelatin solutions, to achieve a target theoretical inorganic content of $\sim 40 \%$ (based on assumed $\mathrm{SiO}_{2}$ content). Hybrid solutions were sealed in Falcon ${ }^{\circledR}$ tubes, then placed in a water bath at $40{ }^{\circ} \mathrm{C}$. The gelatin was initially observed to precipitate upon mixing and then solubilise within 30-40 min. The solutions were held for a further $20 \mathrm{~min}$ prior to cryo-SBS and rheological characterisation, described below.

\section{Fibre production via conventional and cryogenic SBS}

Conventional and cryogenic SBS was conducted based on set-ups previously described for the production of bioactive smooth and porous nanobioactive glass-filled PLA composite fibres [9]. For conventional SBS, neat sol-gel and hybrid precursor solutions (described in "Sol-gel and hybrid fibre precursor formulations for conventional SBS" section) were injected to the inner coax of the SBS head at a rate of $200 \mu \mathrm{L} \mathrm{min}{ }^{-1}$ using a precision syringe driver (N-300, New Era Pump Systems, Inc., Farmingdale, NY, USA). The inner nozzle was surrounded by a high-pressure air sheath, or outer nozzle, through which compressed air was delivered at $0.207 \mathrm{MPa}$ (30 psi) via a Bambi VT150D oil-free and water-free air compressor (Bambi, Italy) and in-line regulator $5 \mathrm{~cm}$ from the SBS head air inlet. The internal diameter (ID) of the SBS inner nozzle was $0.8 \mathrm{~mm}$, outer diameter (OD) $1.8 \mathrm{~mm}$, the outer nozzle had an ID of $2 \mathrm{~mm}$ and OD of $3 \mathrm{~mm}$. The inner nozzle had a tapered end (truncated cone) and set to protrude $2 \mathrm{~mm}$ from the outer nozzle. Fibres were collected at a distance of $30 \mathrm{~cm}$ from the SBS head on a round ( $\sim 15 \mathrm{~cm}$ diameter), static stainless steel collector with spokes $2 \mathrm{~mm}$ diameter (adapted from a computer case fan grill).

Cryo-SBS [9] was conducted using class I and II hybrid formulations described in "Class I and Class II hybrid fibre precursors for cryogenic SBS" section. The solutions were injected separately into the inner nozzle of the SBS head as described above at a rate of $230 \mu \mathrm{L} \mathrm{min}{ }^{-1}$, using outer nozzle pressure supply of $0.138 \mathrm{MPa}$ (20 psi). Fibres were sprayed directly into a bath of liquid $\mathrm{N}_{2}$ at a working distance of $10 \mathrm{~cm}$ and at an angle of $\sim 45^{\circ}$ to the bath. The spraying angle and sheath pressure were selected to limit liquid $\mathrm{N}_{2}$ loss. The bath container was made from an expanded-polystyrene foam box. During cryo-SBS, the level of liquid $\mathrm{N}_{2}$ in the bath was constantly topped-up to ensure that the working distance remained $\pm 2 \mathrm{~cm}$ of the target value $(10 \mathrm{~cm})$. The temperature of the solution was measured at the SBS nozzle, by direct contact with a thermostatic probe, to be $22{ }^{\circ} \mathrm{C}$. Frozen fibre membranes were collected in $50 \mathrm{~mL}$ Falcon $^{\circledR}$ tubes, transferred to lyophilisation flasks (pre-cooled in liquid $\mathrm{N}_{2}$ ) and subsequently lyophilised using a VirTis BenchTop Pro Freeze Dryer (NY, USA). The external glass portion of the lyophilisation flask was kept under liquid $\mathrm{N}_{2}$ using the polystyrene box until a vacuum of $\sim 50$ mTorr had been reached, after which the outside of the flask was left exposed to ambient conditions. Lyophilisation was continued for $72 \mathrm{~h}$, after which the fibres were collected for characterisation. Additionally, porous class I and class II hybrid spheres were formed based on a method previously described by Blaker et al. [9, 61], and briefly solutions were directly dripped into liquid nitrogen and lyophilised as described above.

\section{Rheological characterisation of precursor spinning solutions}

Rheological properties were conducted on precursor spinning solutions as function of shear rate and temperature using an AR-G2 Rheometer (TA Instruments, USA) operated using a cone-plate set-up. Samples of 1-2 $\mathrm{mL}$ were tested. Shear rate measurements were conducted over the range $(\dot{\gamma})\left(10-500 \mathrm{~s}^{-1}\right)$ at 40,30 and $20^{\circ} \mathrm{C}$ for class I, class II and gelatin precursor solutions. Temperature-dependent viscosity measurements made at a constant shear rate of $500 \mathrm{~s}^{-1}$ (as all samples exhibited Newtonian behaviour) as a function of temperature for class I and 
class II. The cryo-SBS hybrid precursors from 40 to $12{ }^{\circ} \mathrm{C}$ over a $10 \mathrm{~min}$ period (equivalent rate $\left.2.8^{\circ} \mathrm{C} \mathrm{min}^{-1}\right)$. The effect of temperature cycling between 20 and $30{ }^{\circ} \mathrm{C}$ was investigated to assess thermoreversible properties. The temperature cycling measurements consisted of a conditioning step at $30{ }^{\circ} \mathrm{C}$ for $2 \mathrm{~min}$ to allow the sample to equilibrate, a peak hold step under constant shear rate $\left(500 \mathrm{~s}^{-1}\right)$ at $30{ }^{\circ} \mathrm{C}$ for $1 \mathrm{~min}$, followed by a conditioning step at $20{ }^{\circ} \mathrm{C}$ for $2 \mathrm{~min}$, and a peak hold step at $20^{\circ} \mathrm{C}$ $\left(500 \mathrm{~s}^{-1}\right)$. Samples were left to relax between each temperature ramp. During the peak hold step, a $10 \mathrm{~s}$ sampling time was used. The temperature cycle was repeated several times for both cryo-SBS class I and II precursor solutions. The viscosity was also measured as a function of time for approximately $75 \mathrm{~min}$ at $40{ }^{\circ} \mathrm{C}$ for class I and II solutions, as well as gelatinGPTMS solution to identify the time point at which extensive crosslinking between the organic and inorganic phase occurred. The class II solution was also measured at $20{ }^{\circ} \mathrm{C}$ over $75 \mathrm{~min}$ to assess the effect of temperature and time on viscosity.

\section{Surface tension measurements of cryogenic spinning precursor solutions}

Surface tension measurements of class I and II hybrid precursors were obtained using a KRÜSS DSA 100 $\left(\mathrm{GmbH}\right.$, Germany) at room temperature $\left(22^{\circ} \mathrm{C}\right)$, mimicking spinning conditions. The surface tension of $10 \% \mathrm{w} / \mathrm{v}$ gelatin (in PBS) and gelatin functionalised with GPTMS ("Class I and Class II hybrid fibre precursors for cryogenic SBS" section) were obtained at $30{ }^{\circ} \mathrm{C}$ as the both were below their gelation point at room temperature. Surface tension was computed for six separate droplets per sample, using Drop Shape Analysis software (KRÜSS GmbH, Germany).

\section{Physical and structural characterisation of sol-gel and hybrid fibres}

\section{Fibre morphology and diameters}

The morphologies of fibres and porous spheres were assessed using scanning electron microscopy on a FEI Sirion FEG-SEM (USA), as well as Hitachi S300 N microscope (USA) for screening. Porous spheres were sectioned using a double-edged Wilkinson Sword ${ }^{\circledR}$ razor blade, as previously described $[9,61]$. Mounted samples were blown with compressed air to remove and loose material and sputter coated with platinum using a Gatan Model 682 Precision Etching Coating System (USA) to an average thickness of $7 \mathrm{~nm}$. Fibre diameters were analysed using ImageJ (version 1.48, $\mathrm{NIH}$, Bethesda, MD, USA) software, from a minimum of 70 fibres.

\section{${ }^{29}$ Si magic angle spinning nuclear magnetic resonance (MAS NMR)}

The solid state ${ }^{29} \mathrm{Si}$ MAS NMR spectra were obtained using a Bruker AVANCE (USA) $400 \mathrm{MHz}$ spectrometer operating at $79.48 \mathrm{MHz}$. The spectra were recorded with a $20^{\circ}$ pulse and a repetition delay of $20 \mathrm{~s}$ (4000 scans) using $4 \mathrm{~mm}$ zirconia rotors spinning at $6 \mathrm{kHz}$. The spectra were referenced against TMS $(0 \mathrm{ppm})$. The degree of condensation $\left(D_{\mathrm{C}}\right)$ was the following equation [25]:

$D_{\mathrm{C}}=\left(\left[\frac{2 T^{2}+3 T^{3}}{3}\right]+\left[\frac{2 Q^{2}+3 Q^{3}+4 Q^{4}}{4}\right]\right) \times 100 \%$

where $T^{n}$ and $Q^{n}$ are the relative abundances of silicon atoms bound to a carbon and $n$ bridging oxygens and silicon atoms bridging to $n$ oxygens, respectively [25].

Thermogravimetric analysis (TGA) for inorganic content determination

TGA was conducted using a TGA-Q500 (TA Instruments, USA) using a dynamic heating regime in air to ensure removal of the organic phase. Samples (2-30 mg) were first equilibrated at $40{ }^{\circ} \mathrm{C}$ for $60 \mathrm{~s}$ to remove trapped water then heated at $10{ }^{\circ} \mathrm{C} \mathrm{min}^{-1}$ to $75{ }^{\circ} \mathrm{C}$, and held $15 \mathrm{~min}$ to perform an isotherm. The temperature was then raised using a high-resolution ramp at $50{ }^{\circ} \mathrm{C} \mathrm{min}^{-1}$ to $400{ }^{\circ} \mathrm{C}$ and held for $30 \mathrm{~min}$, the isotherm ensured complete combustion of the organic phase. Heating was then continued in high-resolution mode at $50{ }^{\circ} \mathrm{C} \mathrm{min}^{-1}$ to $800{ }^{\circ} \mathrm{C}$, at which point the residual mass is representative of the silica content as the gelatin has undergone thermal degradation.

\section{Surface area analysis}

Brunauer-Emmett-Teller (BET) surface area measurements of the fibres were made using a surface area and porosity analyzer (TriStar II, Micromeritics, Neupurkersdorf, Austria). Prior to the gas adsorption 
experiments, impurities were removed via a "degassing" step using a FlowPrep 060 instrument (Micromeritics). Approximately $100 \mathrm{mg}$ (about $1 \mathrm{~cm}^{3}$ ) of each sample was placed inside a glass sample chamber, which was purged with nitrogen at ambient temperature overnight. Afterwards, the nitrogen adsorption isotherms were measured at $77 \mathrm{~K}$.

\section{Wetting of the hybrid fibre membranes by contact angle analysis}

Class I and class II hybrid fibre membranes produced via cryo-SBS were mounted separately on glass microscope slides using thin strips of Scotch ${ }^{\circledR-}$ Magic $^{\mathrm{TM}}$ Tape $(3 \mathrm{M})$ applied at the sample edges to obtain reasonably flat surfaces for measurement. Contact angle measurements were taken on a KRÜSS DSA 100 (GmbH, Germany). Single droplets of water were dropped onto the substrates and the wetting behaviour recorded by video recorded with a built-in high-speed camera.

\section{Results and discussion}

\section{Sol-gel and hybrid fibres via conventional SBS}

Neat sol-gel silica fibres were produced using conventional SBS using a formulation reported by Poologasundarampillai et al. that were previously developed for electrospinning [31]. This formulation was used as a starting point to translate the processing to fibres from electrospinning to SBS. The fibres produced by SBS exhibited smooth surfaces as shown by SEM images (Fig. 1a) and had a mean diameter of $1.7 \pm 0.8 \mu \mathrm{m}$ (Fig. $1 \mathrm{~b}$ ), similar to those produced by electrospinning which were reported in the range 0.5 to $2 \mu \mathrm{m}$ (average $1.0 \pm 0.4 \mu \mathrm{m}$ ) [31]. The rheological behaviour of the neat sol-gel formulation has been previously reported and measured at 290-560 $\mathrm{mPa}$ s at $63 \mathrm{wt} \%$ solvent evaporated [31]. The molar ratio of water to TEOS was two which may result in the formation of more linear silica chains in agreement with Orefice and Hench [32]. The rate of fibre formation is faster via SBS, with injection rates of $230 \mu \mathrm{L} \mathrm{min}{ }^{-1}$ compared to $31.8 \mu \mathrm{L} \mathrm{min}{ }^{-1}$ previously reported for electrospinning [31].

SBS hybrid precursors from the formulations developed above were successfully spun into fibres and exhibit a rougher morphology (Fig. 1c) compared to the neat sol-gel fibres. The hybrid fibres have very similar diameters and distributions (Fig. 1d) to the sol-gel fibres. The hybrid formulation was more challenging to spin due to the relatively short processing window (shown in Fig. 1e). Within 20-min post-mixing of the spinning precursor being prepared, the solution was too fluid and droplet spray resulted; however, there was a limited window between 30 and 40 min that enabled fibre production, beyond $40 \mathrm{~min}$ the precursor solution gelled rapidly and could no longer be sprayed. The short window in which the fibres could be spun demonstrates issues in controlling the viscosity. The precursors had a viscosity of $80 \pm 1$ and $157 \pm 1 \mathrm{mPa} \mathrm{s}$ after 30 and $40 \mathrm{~min}$, respectively (Fig. 1e). The viscosity increases over time, governed by acid concentration, temperature, and solvent evaporation [31, 62]. Whilst the viscosity can be lowered by the addition of alcohol in TEOS-based sol-gel systems [44, 45], increasing the concentration of alcohol caused precipitation of gelatin in the hybrid formulations.

\section{Class I and class II hybrid fibres and spheres via cryogenic SBS}

\section{Class I and II hybrid solution rheological properties}

Ethanol in the above formulations was swapped for TBA to enable facile lyophilisation. Highly porous silica nanoparticles have previously been prepared using TBA and a basic catalyst [59]. Su et al. [59] previously obtained high surface area cryogels using a molar ratio of 13 (TBA:TEOS). In the current work, a molar ratio of 5 (TBA:TEOS) was used as higher concentrations of TBA lead to the precipitation of gelatin [63]. The gelatin solution was effectively diluted from 10 to $5.2 \% \mathrm{w} / \mathrm{v}$ on addition to the inorganic precursor solution, to obtain a total solute concentration of $\sim 9 \%$ in the hybrid spinning solution given $100 \%$ conversion of TEOS to $\mathrm{SiO}_{2}$.

The viscosity of class I and class II cryo-SBS precursor solutions, as a function of shear rate at 20,30 and $40^{\circ} \mathrm{C}$, is shown in Fig. 2a. These temperatures were selected as they represent the preparation, dissolution and reaction conditions, and an intermediate point cooling down to spinning at room temperature. All precursors exhibit Newtonian behaviour at shear rates above $100 \mathrm{~s}^{-1}$. Orefice and Hench [32] reported initial shear thinning of bioactive sol-gels followed 

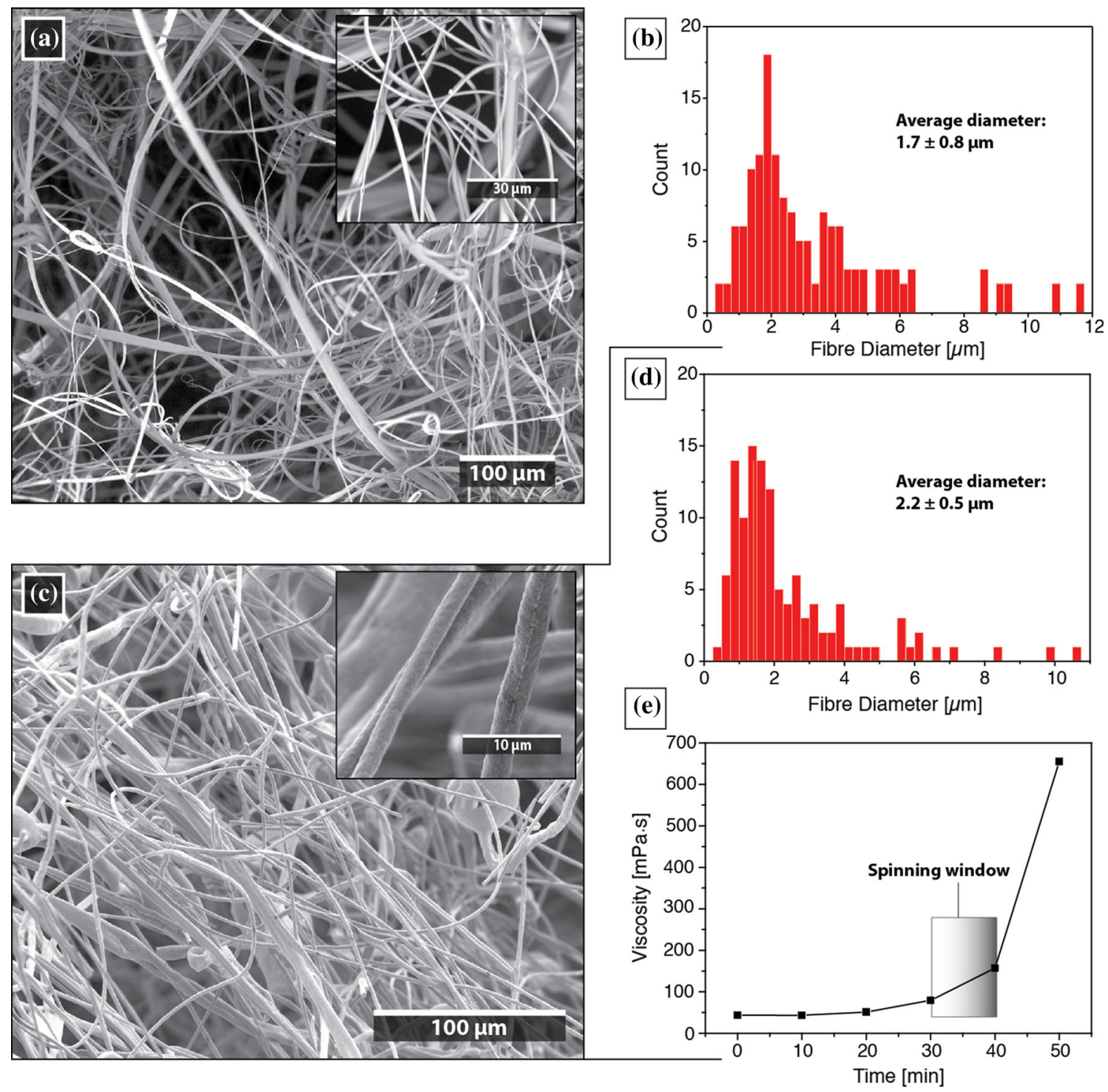

Figure 1 SEM images of sol-gel fibres (a) and hybrid silica-gelatin fibres (c) produced by conventional SBS, their size distribution (b, d, respectively), and the viscosity profile of hybrid precursor solution as a function of time (e).

by Newtonian flow above shear rates of $10 \mathrm{~s}^{-1}$. They indicate that a water to alkoxide molar ratio of 2 yielded a linear polymeric precursor that is amenable to the spinning process [32]. Despite the higher water to alkoxide (TEOS) molar ratio used in the current work, the incorporation of gelatin (in solution) also facilitated the spinning process by providing entanglements. Both class I and II solutions exhibit an increase in viscosity with decreasing temperatures, which is more marked for the class II solutions. Class II solutions are more viscous due to the development of covalent crosslinks, further evidenced below. The temperature-dependent viscosity was investigated at constant shear rate $\left(500 \mathrm{~s}^{-1}\right)$, both classes exhibit a rapid increase in viscosity below $20^{\circ} \mathrm{C}$ (Fig. 2b). The typical sol-gel transition for the $10 \% \mathrm{w} / \mathrm{v}$ gelatin solution is shown in Fig. S1. Below $23{ }^{\circ} \mathrm{C}$ the $10 \% \mathrm{w} /$ $\mathrm{v}$ gelatin solution exhibits a sharp increase in viscosity (to $2949 \mathrm{mPa} \mathrm{s}$ at $15.3^{\circ} \mathrm{C}$ ), indicative of the thermally activated conformation change from random coil to triple helix $[57,64]$. The hybrid solutions exhibit a similar rapid increase in viscosity, below $20{ }^{\circ} \mathrm{C}$ and occurring over a wider temperature range (to $\sim 12{ }^{\circ} \mathrm{C}$ ), likely due to the increased dilution. The extended range is also likely due to lower $\mathrm{pH}$ of the hybrid formulations and some protonation of the gelatin (class I pH 3.9 and class II pH 4.1, gelatin $\mathrm{pH}$ 6.2, gelatin-GPTMS $\mathrm{pH}$ 6.7). 

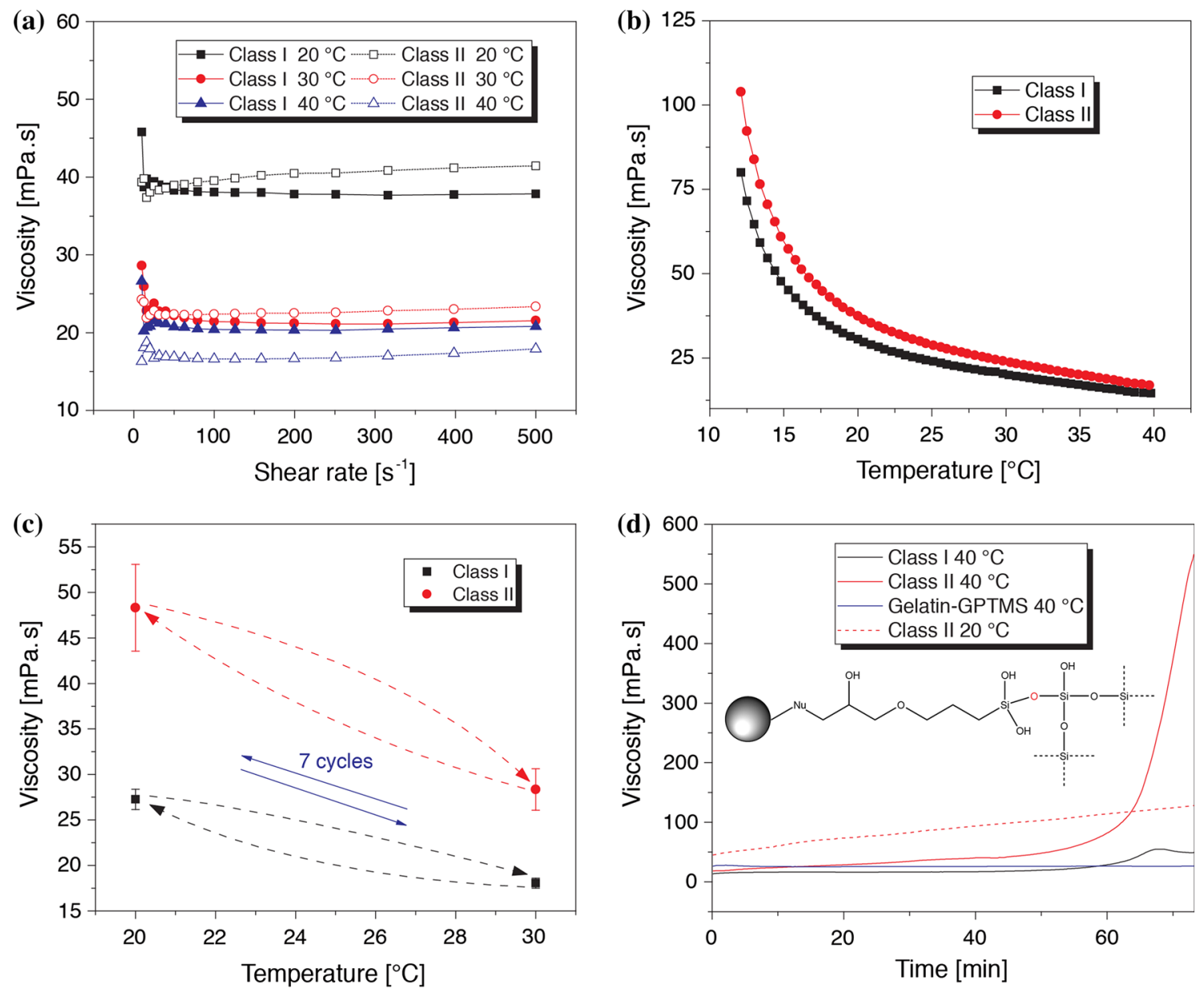

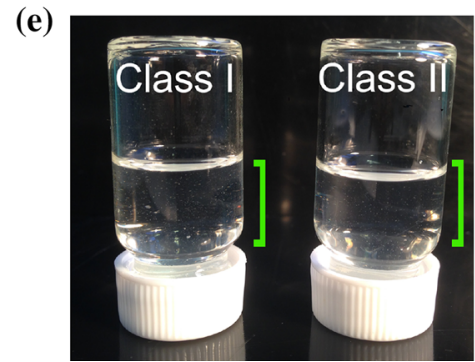

Figure 2 Rheology of precursor class I and class II solutions as function of shear rate at 20,30 , and $40{ }^{\circ} \mathrm{C}$ (a), temperaturedependent viscosity of class I and class II solutions at constant shear rate $\left(500 \mathrm{~s}^{-1}\right)(\mathrm{b})$, thermoreversibility demonstrated over seven cycles for class I and II solutions (c), viscosity profiles of class I, class II and gelatin-GPTMS solutions as function of time

The thermoreversibility of the hybrid formulations was tested by cycling the precursors between 30 and $20{ }^{\circ} \mathrm{C}$, and measuring the viscosity at constant shear $\left(500 \mathrm{~s}^{-1}\right)$ (Fig. 1c). The viscosity varied between $27.3 \pm 1.1\left(20^{\circ} \mathrm{C}\right)$ to $18.1 \pm 0.6\left(30{ }^{\circ} \mathrm{C}\right) \mathrm{mPa} \mathrm{s}$ and $48.3 \pm 4.8\left(20^{\circ} \mathrm{C}\right)$ to $28.4 \pm 2.3\left(30^{\circ} \mathrm{C}\right) \mathrm{mPa}$ s for class I and II hybrid precursors, respectively. The viscosity

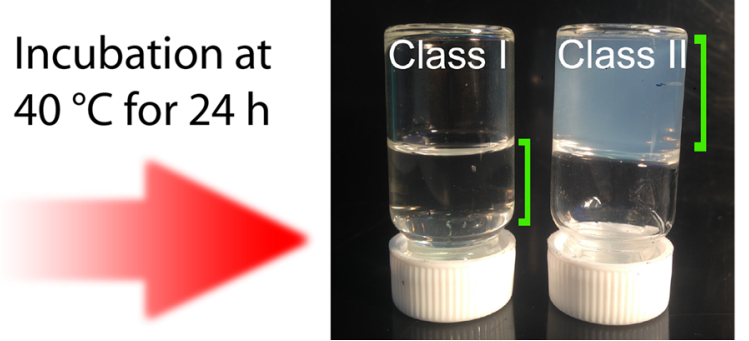

and temperature $\left(\mathbf{d},{ }^{*} N u\right.$ signifies nucleophile in the scheme for functionalised gelatin-GPTMS), class II markedly increases with time due to crosslinking and network formation. Images of class I and II at $40{ }^{\circ} \mathrm{C}$ upon mixing and at $24 \mathrm{~h}$ (e), class II gels, whereas class I remains fluid.

is tuneable in the $20-30{ }^{\circ} \mathrm{C}$ range. The class II solution also exhibits time-dependent behaviour due to the formation of covalent bonds between gelatin and silica network, a rapid increase in viscosity is observed for the sample held at $40{ }^{\circ} \mathrm{C}$ after $65 \mathrm{~min}$ (Fig. 1d), whereas the class I solution exhibited an increase in viscosity at $\sim 65 \mathrm{~min}$, then a plateau 
region (behaviour was exhibited in three repeats, representative profile shown). The gelatin-GPTMS solution underwent no significant change in the measurement period. The class II solution held at $20{ }^{\circ} \mathrm{C}$ exhibited a near linear increase in viscosity over time (Fig. 1d). As expected, the development of the silica network and covalent crosslinking is time- and temperature-dependent, and both can be used to control the viscosity and spinning window. The crosslinking reaction between the organic and inorganic phases via GPTMS is catalysed by heat and after extended periods of time the class II solutions gel irreversibly (images shown in Fig. 1e). After $24 \mathrm{~h}$ of incubation at $40{ }^{\circ} \mathrm{C}$, the class II solution irreversibility forms a gel whereas the class I solution remains as a viscous solution. Irreversibility was also evident if the gelatin-GPTMS functionalisation reaction proceeded for an extended period of time, the hydrolysed trimethoxysilane terminal groups of GPTMS begin to polycondense and then become insoluble in the inorganic precursor phase, in agreement with Negahi Shirazi et al. [60].

The surface tension of the gelatin, functionalised gelatin, silica precursors, class I, and class II solutions are shown in Table 1. The gelatin and gelatin-GPTMS solution had a similar surface tension of $51.2 \pm 2.5$ and $47.4 \pm 6.3 \mathrm{mN} \mathrm{m}^{-1}$, respectively, at $30{ }^{\circ} \mathrm{C}$. Upon addition of the silica precursor, the surface tension was reduced to $24.8 \pm 1$ and $25.7 \pm 0.5 \mathrm{mN} \mathrm{m}^{-1}$ for class I and class II at room temperature, respectively. The TBA contributed to reduce the surface tension, with its hydrophobic methyl groups. The decrease in surface tension of the gelatin solutions after mixing with the silica precursor indicates that the surface tension is governed by the inorganic component. The surface tension of the class I and II solutions corresponds to polymer solutions that have been successfully spun into fibres via SBS. PLA solutions (in chloroform, dichloromethane and chloroform/acetone mixtures) with surface tensions in the range 26-34 $\mathrm{mN} \mathrm{m}^{-1}$ have all been successfully spun into fibres via SBS [65-67].

Whilst the rheological properties can give an indication of spinnability, an important consideration is that the shear, solvent evaporation and degree of polycondensation are influenced during fibre spinning as the precursor is drawn into a fibre and the solution is exposed to rapidly moving air at the nozzle exit.
Table 1 Surface tension of cryo-SBS precursor solutions

\begin{tabular}{ll}
\hline Sample & Surface tension $\left(\mathrm{mN} \mathrm{m}^{-1}\right)$ \\
\hline Gelatin solution & $51.2 \pm 2.5$ \\
Gelatin-GPTMS solution & $47.4 \pm 6.3$ \\
Silica precursor solution (cryo-SBS) & $24.1 \pm 0.4$ \\
Class I solution & $24.8 \pm 1.0$ \\
Class II solution & $25.7 \pm 0.6$ \\
\hline
\end{tabular}

Porous sphere and fibre morphologies, fibre size distributions

In order to test the ability of the solutions to be frozen and lyophilised to form porous structures, class I and class II solutions containing TBA were manually dripped via a syringe with a 25-g needle directly into liquid nitrogen. The frozen spheres were collected and lyophilised. The lyophilised spheres exhibit a porous skin region (Fig. 3a) and a highly porous interior (sectioned sphere, Fig. 3b, and inset). Class I and class II spheres exhibited very similar internal and external morphologies. The spheres produced were $\sim 2 \mathrm{~mm}$ in diameter. Porous, composite poly(D,L-lactide) (PDLLA)/nanobioactive glass-filled spheres have been produced via the TIPS process $[9,61]$, and the size of neat porous PDLLA spheres can be reduced to $<1 \mu \mathrm{m}$ using vibrating needles or SBS of low viscosity solutions [61]. It should therefore be possible by extension to produce hybrid porous spheres of similarly small diameters by vibrating needle/atomisation techniques, whilst porous solgel/hybrid foam monoliths have previously been formed by freezing vials containing aged gels into liquid nitrogen and lyophilised here are issues with cell infiltration $[25,29,38]$. Whereas the inter-sphere void size can be controlled by sphere size as well as packing efficiencies, such spheres may also have application in bioreactors for cell expansion.

Both class I and class II lyophilised hybrid fibres exhibited cotton-wool like structures, as shown in Fig. $4 a, b$, respectively. There is some evidence of bead formation (porous beads/spheres), both in line with the fibres and entangled within the fibre membrane, more prevalent for class II fibres. Droplet/bead formation is a result of the high driving force at the SBS nozzle causing Rayleigh instability [68]. SEM analysis revealed both class I and II fibres rough surface morphologies, shown at low magnification in Fig. 4c, d, respectively. In both cases, the fibres are seen to exhibit 

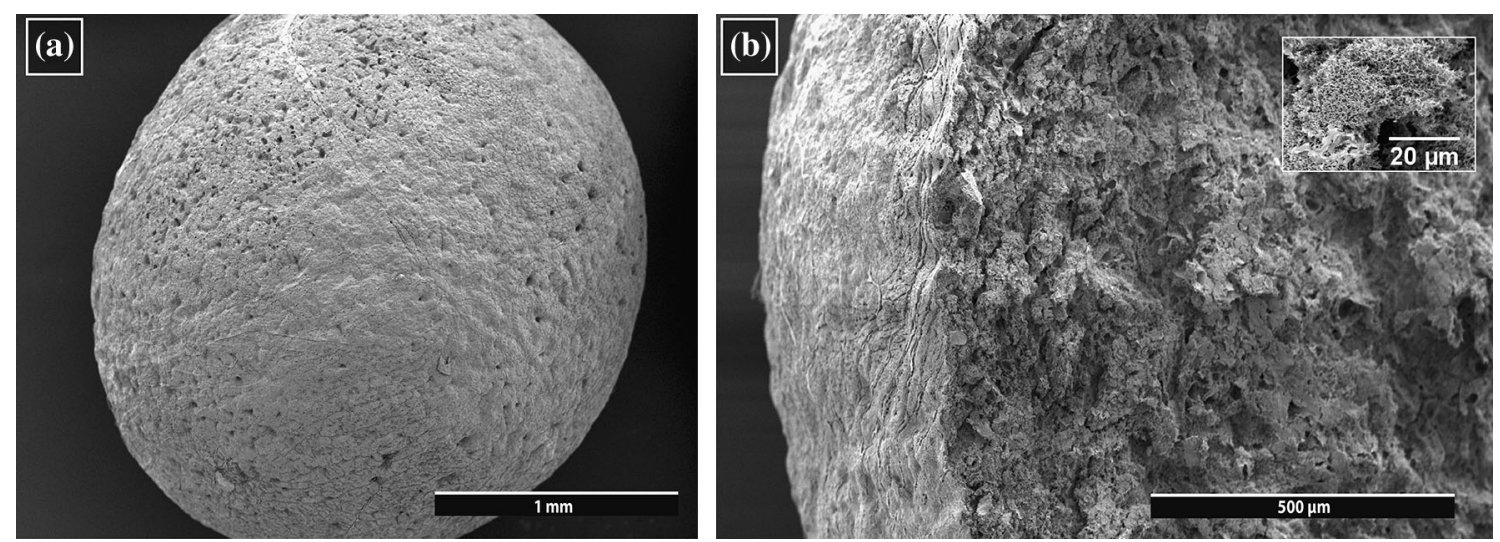

Figure 3 SEM images of silica-gelatin hybrid porous spheres produced by dripping into liquid nitrogen and lyophilisation, sphere exterior (a) and interior (b).

a more roughened surface topography, which is distinct in comparison with fibres produced by conventional SBS [69] and electrospinning [31]. The surface roughness is hypothesised to result from thermally induced phase separation occurring as the fibres contact the liquid nitrogen. The excess solvent is removed by the lyophilisation process leaving behind the texture that is seen throughout the fibres. High-magnification SEM images of the fracture surfaces of the fibres (class I and II, Fig. 4e, f, respectively) reveal a highly porous interior and a thin skin region, similar in appearance to the porous spheres described above. Class I and II porous fibres exhibit mean diameters $4.4 \pm 1.7$ and $5.8 \pm 2.1 \mu \mathrm{m}$, respectively (fibre size distributions are shown in Fig. $4 \mathrm{~g}$, h, respectively). The higher diameter observed for the class II fibres is likely due to the higher viscosity of the precursor solution, stemming from organic-inorganic covalent crosslinking. The fibre diameters for both porous class I and II hybrids are larger in comparison with those produced by conventional SBS in the work presented here, and electrospun hybrid fibres were produced by others. As previously mentioned, authors achieved fibres diameters of $192.6 \pm 8$ and $239 \pm 13 \mathrm{~nm}$ by electrospinning gelatin/silica and chitosan-PEO/silica hybrids, respectively $[47,49]$. Despite the relatively large fibre size distribution, class II fibres in the range of $700 \mathrm{~nm}$ were obtained. It should be possible to adjust the formulation and processing parameters to obtain more consistent fibres of smaller diameters.

\section{Structural characterisation and inorganic content}

The ${ }^{29} \mathrm{Si}$ MAS NMR spectra evidence the structure the silica network has within the hybrid fibres, shown in
Fig. 5a, b. Both class I and class II fibres show strong peaks corresponding to a $Q^{3}$ species, silicon bonded to three other silicon atoms by bridging oxygens. $Q^{n}$ species are standard in networks formed from TEOS as a precursor, and the smaller $Q^{4}$ peak is a result of the network formation occurring under non-ideal conditions and is seen commonly in the literature [44, 62, 70]. In the class II fibres, peaks can also be seen around -56.3 and $-64.3 \mathrm{ppm}$ which correspond to the $T^{2}$ and $T^{3}$ species, a silicon atom bonded to 2 and 3 carbon atoms, respectively, via bridging oxygen atoms [71]. The signal form the $T^{n}$ species was very low in comparison with the $Q^{n}$ structure due to the concentration differences between the two species (molar ratio of 1:30 GPTMS to TEOS).

The degree of condensation was lower in the hybrids formed here in comparison with those reported in the literature due to the high $Q^{3}$ abundance. The higher $Q^{3}$ abundancy is a result of the procedure used to make the silica precursor, i.e., reaction time, acid concentration, temperature, and TEOS concentration. The degree of condensation $\left(D_{\mathrm{c}}\right)$ for the class I fibres was $83.6 \%$, which was slightly higher than the $D_{c}$ of the class II fibres $(78.0 \%)$, as calculated with Eq. (1). The lower $D_{c}$ in the class II fibres was likely due to the incorporation of GPTMS that leads to the relative abundance of the $T^{n}$ species skewing the $D_{\mathrm{c}} \cdot{ }^{29} \mathrm{Si}$ MAS NMR provides an insight to the structure of the silica network; it does not confirm crosslinking between the organic and inorganic phases in the form of $\mathrm{C}-\mathrm{Si}-\mathrm{O}-\mathrm{Si}-\mathrm{O}$. The $T^{n}$ species can react with either the hydroxyl groups of the silica network or another hydrolysed trimethoxysilane terminal. Coincidentally, the $T^{n}$ species may just represent crosslinked gelatin. 

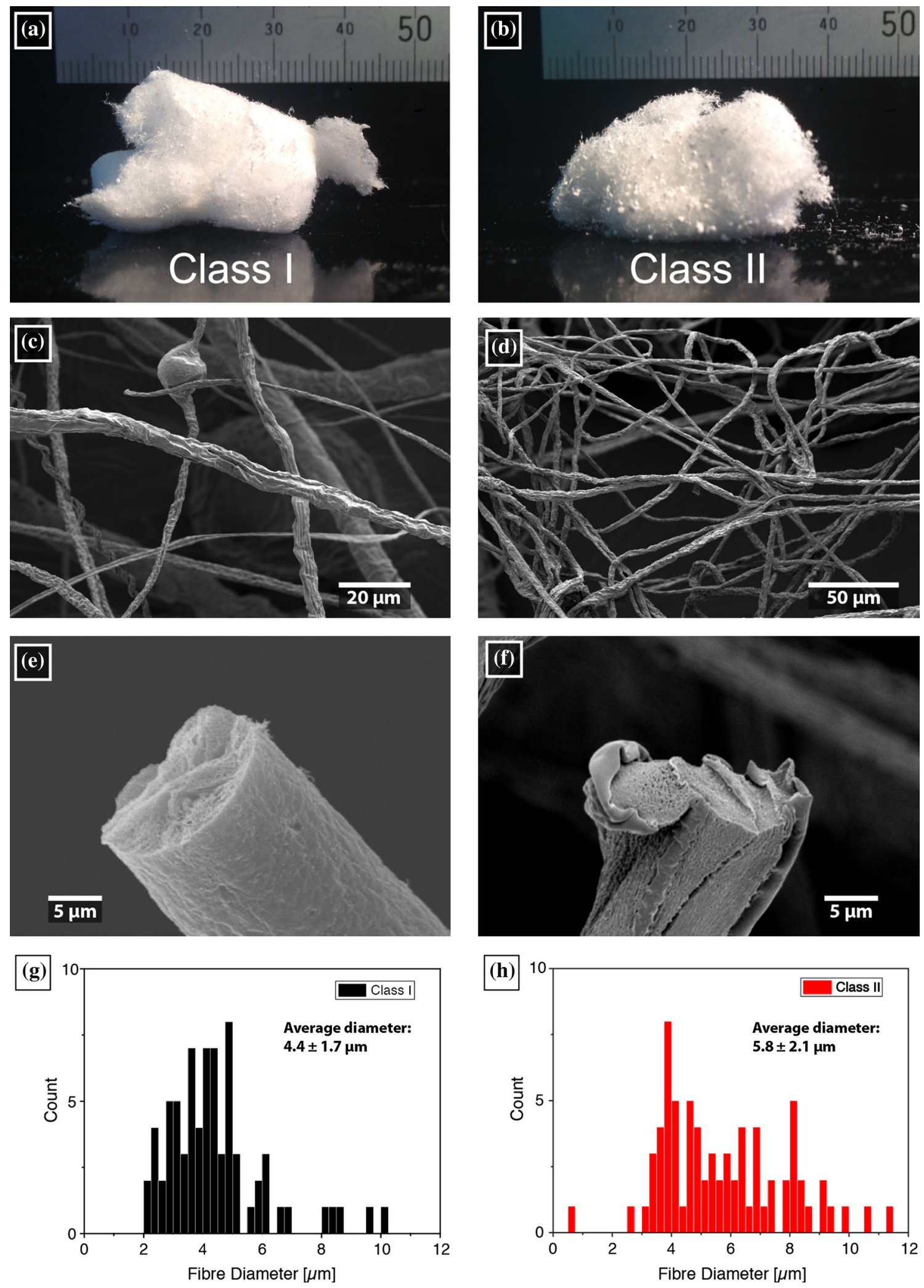

Figure 4 Photographs of silica-gelatin porous class I (a) and class II (b) hybrid fibres, (ruler scale mm). SEM images porous hybrid fibres, at low magnification (c) class I (d) class II, and high-

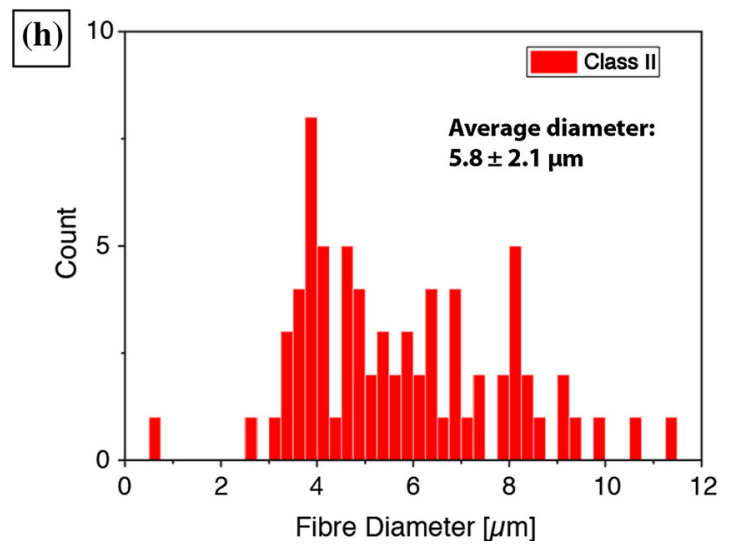

magnification cross sections (e) class I and (f) class II. Fibre size distributions for class I (g) and class II fibres (h). 

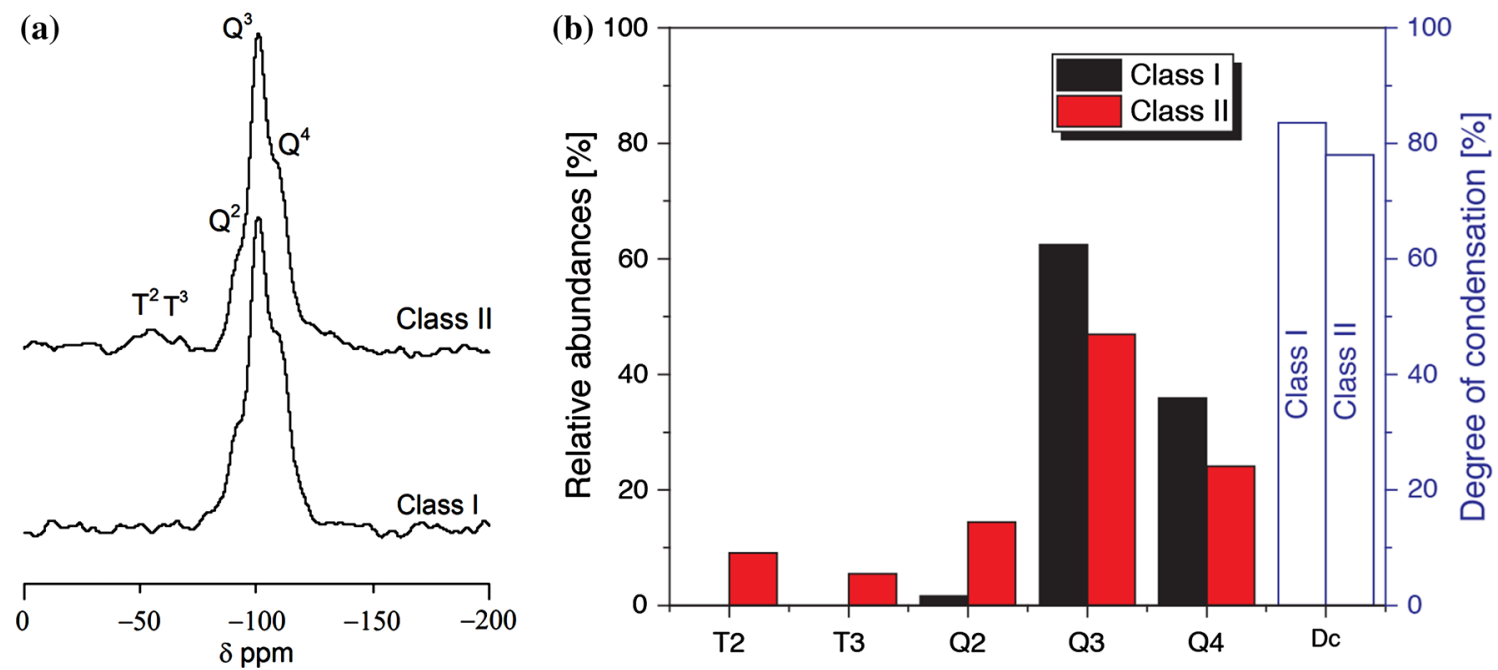

Figure $5{ }^{29} \mathrm{Si}$ MAS NMR of class I and class II fibres, with $Q$ and $T$ species indicated (a). The degree of condensation in both class I and II, and relative abundances of the $Q^{n}$ and $T^{n}$ species (b).

Further, the class II fibres do not undergo dissolution when immersed in water, due in part to bridging between gelatin chains rather than the inorganic phase [72]. However, over the period of an hour, the viscosity of the gelatin-GPTMS solution remains constant (Fig. 2d), whereas the viscosity of the class II solution increases due to organic-inorganic bridging (Fig. 2d) and therefore suggests that the dissolution properties of the class II fibres are due to organicinorganic bridging.

The reaction between GPTMS and gelatin has been extensively covered and characterised in the literature [25, 38, 60, 73, 74]. The methodology reported by Negahi Shirazi et al. [60] was used in the current work to functionalise gelatin with GPTMS, buffering the $\mathrm{pH}$ to 7.4 to reduce hydrolysis and polycondensation of the trimethoxysilane terminal and diol formation of the epoxy ring. Although Gabrielli et al. [73] reported that at a lower $\mathrm{pH}$ the rate of epoxide ring opening and hydrolysis increased, it was not determined for basic conditions due to precipitation. At a neutral $\mathrm{pH}$ (in PBS), it has been reported that GPTMS is very stable; however, the presence of nucleophiles catalyses the ring opening reaction [75, 76]. In the current work, nucleophiles on the gelatin chains (carboxylic acid and amine groups) as well as the elevated temperature $\left(40{ }^{\circ} \mathrm{C}\right)$ acted as the catalyst for the ring opening reaction, according to [60].

Theoretically, given complete hydrolysis and $100 \%$ efficiency of the polycondensation reaction, the fibres should have 42 and $43 \mathrm{wt} \%$ inorganic for the class I and II fibres, respectively. TGA results show that the inorganic content in the class I and II fibres was $38.4 \pm 1.8$ wt\% (Fig. 6a) and $38.6 \pm 1.6 \%$ wt (Fig. 6b), indicating a polycondensation mean reaction efficiently of, $91.43 \pm 4.29$ and $89.77 \pm 3.72 \%$, both, respectively. Several reports have highlighted an organic phase is in the region of $50-70 \%$ and is beneficial to impart flexibility to the hybrid $[28,29,47,77,78]$.

\section{Surface area and wettability}

BET surface areas of class I and class II fibres produced via cryo-SBS were measured to be $3.4 \pm 0.2$ and $9.5 \pm 0.3 \mathrm{~m}^{2} \mathrm{~g}^{-1}$, respectively. Medeiros et al. [9] reported surface areas of $43.5 \mathrm{~m}^{2} \mathrm{~g}^{-1}$ when applying the cryo-SBS to PLA fibres although McCann et al. [79] reported surface areas of $\sim 9.5 \mathrm{~m}^{2} \mathrm{~g}^{-1}$ for poly(acrylonitrile) (PAN) fibres with the diameter of $1 \mu \mathrm{m}$ using cryogenic electrospinning. Water droplets rapidly wicked into both the class I and class II cryoSBS porous hybrid fibre mats in the range of 0.6-4 s. The wettability is in contrast to porous fibres produced by cryo-SBS based on nanobioactive glass-filled/PDLLA, which have been shown to exhibit high apparent water-in-air contact angles, $\sim 140^{\circ}$ and may require surface treatment.

It remains a further challenge to truly incorporate calcium into the silica network of sol-gel hybrid fibres to allow the controlled release of therapeutic ions. Calcium has been incorporated using calcium 

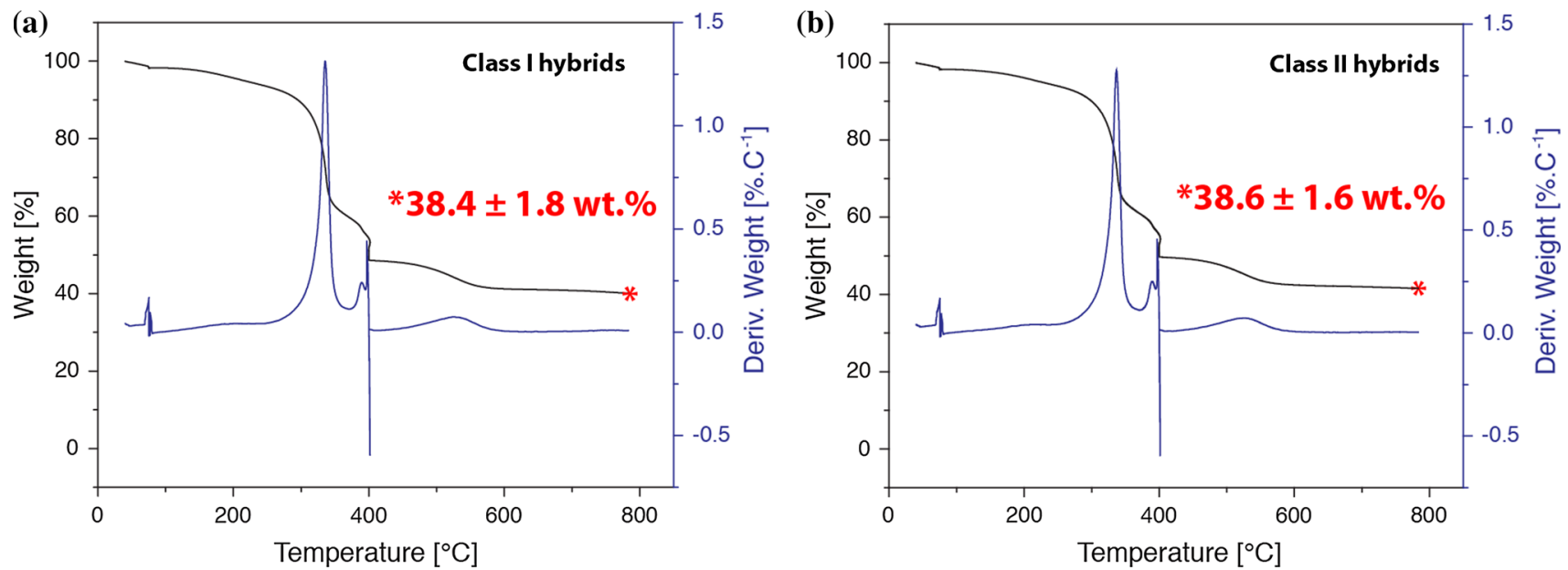

Figure 6 Thermogravimetric analysis to determine inorganic content for class I (a) and class II (b) hybrid fibres.

chloride and calcium nitrate tetrahydrate; however, it has been highlighted that the calcium does not enter the silica network without thermal treatment and therefore is not appropriate for the hybrid materials developed here [35, 36, 48, 49, 80]. Calcium alkoxide precursors appear a more promising route and have been used to obtain monoliths and fibres with homogeneous silica and calcium networks without the need for thermal treatment [46, 72, 77, 81]. The incorporation of calcium into the porous fibres using calcium alkoxides in the formulations and processing is the focus of current work.

\section{Conclusion}

Sol-gel silica and inorganic-organic silica-gelatin hybrids have been formed into fibres via solution blow spinning. The spinning window, however, is rather short, and the process is challenging to control. Formulations have been developed by replacing ethanol with tert-butanol (TBA), which has a higher melting point, forms azeotropes with water and ethanol, and is relatively facile to freeze and remove via lyophilisation. TEOS/gelatin hybrid formulations containing TBA could be dripped directly into liquid nitrogen and lyophilised to realise highly porous class I and II hybrid spheres. The reversible thermally activated conformation transition of gelatin from random coil to triple helix was exploited to tune formulation viscosity and therefore enable cryogenic solution blow spinning to be conducted. The resultant class I and II fibres exhibited porous structures, which should extend the degradation, ion release and mechanical property ranges of these materials. The in vitro behaviour and inclusion of calcium and other therapeutic ions is the focus of current research.

\section{Acknowledgements}

JJB and ESM acknowledge support from CNPq (Brazil), Grant Number PVE 304898/2014-7, respectively. JJB, RG and WSA are grateful for the technical input and experimental assistance of Polly Greensmith.

Open Access This article is distributed under the terms of the Creative Commons Attribution 4.0 International License (http://creativecommons.org/ licenses/by/4.0/), which permits unrestricted use, distribution, and reproduction in any medium, provided you give appropriate credit to the original author(s) and the source, provide a link to the Creative Commons license, and indicate if changes were made.

Electronic supplementary material: The online version of this article (doi:10.1007/s10853-017-08681) contains supplementary material, which is available to authorized users.

\section{References}

[1] Santos AMC, Medeiros ELG, Blaker JJ, Medeiros ES (2016) Aqueous solution blow spinning of poly(vinyl alcohol) micro- and nanofibers. Mater Lett 176:122-126 
[2] Medeiros ES, Glenn GM, Klamczynski AP, Orts WJ, Mattoso LHC (2009) Solution blow spinning: a new method to produce micro- and nanofibers from polymer solutions. J Appl Polym Sci 113(4):2322-2330

[3] Behrens AM, Casey BJ, Sikorski MJ, Wu KL, Tutak W, Sandler AD, Kofinas P (2014) In situ deposition of PLGA nanofibers via solution blow spinning. ACS Macro Lett 3(3):249-254

[4] Srinivasan S, Chhatre SS, Mabry JM, Cohen RE, McKinley GH (2011) Solution spraying of poly(methyl methacrylate) blends to fabricate microtextured, superoleophobic surfaces. Polymer 52(14):3209-3218

[5] Stojanovska E, Canbay E, Pampal ES, Calisir MD, Agma O, Polat Y, Simsek R, Gundogdu NAS, Akgul Y, Kilic A (2016) A review on non-electro nanofibre spinning techniques. RSC Adv 6(87):83783-83801

[6] Daristotle JL, Behrens AM, Sandler AD, Kofinas P (2016) A review of the fundamental principles and applications of solution blow spinning. ACS Appl Mater Interfaces 8(51):34951-34963

[7] Tutak W, Sarkar S, Lin-Gibson S, Farooque TM, Jyotsnendu G, Wang D, Kohn J, Bolikal D, Simon CG Jr (2013) The support of bone marrow stromal cell differentiation by airbrushed nanofiber scaffolds. Biomaterials 34(10):2389-2398

[8] Sohier J, Corre P, Perret C, Pilet P, Weiss P (2014) Novel and simple alternative to create nanofibrillar matrices of interest for tissue engineering. Tissue Eng Part C 20(4):285-296

[9] Medeiros ELG, Braz AL, Porto IJ, Menner A, Bismarck A, Boccaccini AR, Lepry WC, Nazhat SN, Medeiros ES, Blaker JJ (2016) Porous bioactive nanofibers via cryogenic solution blow spinning and their formation into $3 \mathrm{~d}$ macroporous scaffolds. ACS Biomater Sci Eng 2(9):1442-1449

[10] Kuk E, Ha Y-M, Yu J, Im I-T, Kim Y, Jung YC (2016) Robust and flexible polyurethane composite nanofibers incorporating multi-walled carbon nanotubes produced by solution blow spinning. Macromol Mater Eng 301(4):364370

[11] Li L, Kang W, Zhuang X, Shi J, Zhao Y, Cheng B (2015) A comparative study of alumina fibers prepared by electroblown spinning (EBS) and solution blowing spinning (SBS). Mater Lett 160:533-536

[12] Farias RMC, Menezes RR, Oliveira JE, de Medeiros ES (2015) Production of submicrometric fibers of mullite by solution blow spinning (SBS). Mater Lett 149:47-49

[13] Cena CR, Behera AK, Behera B (2016) Structural, dielectric, and electrical properties of lithium niobate microfibers. J Adv Ceram 5(1):84-92

[14] Cheng B, Tao X, Shi L, Yan G, Zhuang X (2014) Fabrication of $\mathrm{ZrO} 2$ ceramic fiber mats by solution blowing process. Ceram Int 40(9, Part B):15013-15018
[15] Abdal-hay A, Hamdy AS, Lim JH (2014) Facile preparation of titanium dioxide micro/nanofibers and tubular structures by air jet spinning. Ceram Int 40(10, Part A):15403-15409

[16] Hegemann D, Brunner H, Oehr C (2003) Plasma treatment of polymers for surface and adhesion improvement. Nucl Instrum Methods Phys Res Sect B 208:281-286

[17] Zanini S, Orlandi M, Colombo C, Grimoldi E, Riccardi C (2009) Plasma-induced graft-polymerization of polyethylene glycol acrylate on polypropylene substrates. Eur Phys J D 54(2):159-164

[18] Jones JR (2013) Review of bioactive glass: from Hench to hybrids. Acta Biomater 9(1):4457-4486

[19] Boccaccini AR, Blaker JJ (2005) Bioactive composite materials for tissue engineering scaffolds. Expert Rev Med Devices 2(3):303-317

[20] Liu X, Rahaman MN, Hilmas GE, Bal BS (2013) Mechanical properties of bioactive glass (13-93) scaffolds fabricated by robotic deposition for structural bone repair. Acta Biomater 9(6):7025-7034

[21] Mačković M, Hoppe A, Detsch R, Mohn D, Stark WJ, Spiecker E, Boccaccini AR (2012) Bioactive glass (type 45S5) nanoparticles: in vitro reactivity on nanoscale and biocompatibility. J Nanopart Res 14(7):966

[22] Brunner TJ, Grass RN, Stark WJ (2006) Glass and bioglass nanopowders by flame synthesis. J Chem Soc Chem Commun 13:1384-1386

[23] Rezwan K, Chen QZ, Blaker JJ, Boccaccini AR (2006) Biodegradable and bioactive porous polymer/inorganic composite scaffolds for bone tissue engineering. Biomaterials 27(18):3413-3431

[24] Novajra G, Perdika P, Pisano R, Miola M, Bari A, Jones JR, Detsch R, Boccaccini AR, Vitale-Brovarone C (2015) Structure optimisation and biological evaluation of bone scaffolds prepared by co-sintering of silicate and phosphate glasses. Adv Appl Ceram 114:S48-S55

[25] Mahony O, Yue S, Turdean-Ionescu C, Hanna JV, Smith ME, Lee PD, Jones JR (2014) Silica-gelatin hybrids for tissue regeneration: inter-relationships between the process variables. J Sol-gel Sci Technol 69(2):288-298

[26] Pereira MM, Jones JR, Orefice RL, Hench LL (2005) Preparation of bioactive glass-polyvinyl alcohol hybrid foams by the sol-gel method. J Mater Sci Mater Med 16(11):1045-1050

[27] Pereira MM, Jones JR, Hench LL (2005) Bioactive glass and hybrid scaffolds prepared by sol-gel method for bone tissue engineering. Adv Appl Ceram 104(1):35-42

[28] Wang D, Romer F, Connell L, Walter C, Saiz E, Yue S, Lee PD, McPhail DS, Hanna JV, Jones JR (2015) Highly flexible silica/chitosan hybrid scaffolds with oriented pores for tissue regeneration. J Mater Chem B 3(38):7560-7576 
[29] Connell LS, Romer F, Suarez M, Valliant EM, Zhang Z, Lee PD, Smith ME, Hanna JV, Jones JR (2014) Chemical characterisation and fabrication of chitosan-silica hybrid scaffolds with 3-glycidoxypropyl trimethoxysilane. J Mater Chem B 2(6):668-680

[30] Lemos EMF, Patricio PSO, Pereira MM (2016) 3D nanocomposite chitosan/bioactive glass scaffolds obtained using two different routes: an evaluation of the porous structure and mechanical properties. Quim Nova 39(4):462-466

[31] Poologasundarampillai G, Wang D, Li S, Nakamura J, Bradley R, Lee PD, Stevens MM, McPhail DS, Kasuga T, Jones JR (2014) Cotton-wool-like bioactive glasses for bone regeneration. Acta Biomater 10(8):3733-3746

[32] Orefice RL, Hench LL, Clark AE, Brennan AB (2000) Novel sol-gel bioactive fibers. J Biomed Mater Res 55(4):460-467

[33] Pereira MM, Clark AE, Hench LL (1994) Calcium phosphate formation on sol-gel-derived bioactive glasses in vitro. J Biomed Mater Res Part A 28(6):693-698

[34] Pereira MM, Clark AE, Hench LL (1995) Effect of texture on the rate of hydroxyapatite formation on gel-silica surface. J Am Ceram Soc 78(9):2463-2468

[35] Yu B, Turdean-Ionescu CA, Martin RA, Newport RJ, Hanna JV, Smith ME, Jones JR (2012) Effect of calcium source on structure and properties of sol-gel derived bioactive glasses. Langmuir 28(50):17465-17476

[36] Lin S, Ionescu C, Pike KJ, Smith ME, Jones JR (2009) Nanostructure evolution and calcium distribution in sol-gel derived bioactive glass. J Mater Chem 19(9):1276-1282

[37] Valliant EM, Jones JR (2011) Softening bioactive glass for bone regeneration: sol-gel hybrid materials. Soft Matter 7(11):5083-5095

[38] Mahony O, Tsigkou O, Ionescu C, Minelli C, Ling L, Hanly R, Smith ME, Stevens MM, Jones JR (2010) Silica-gelatin hybrids with tailorable degradation and mechanical properties for tissue regeneration. Adv Funct Mater 20(22):3835-3845

[39] Miguez-Pacheco V, Hench LL, Boccaccini AR (2015) Bioactive glasses beyond bone and teeth: emerging applications in contact with soft tissues. Acta Biomater 13:1-15

[40] Kickelbick G (2007) Introduction to hybrid materials. Hybrid materials. Wiley, Weinheim, pp 1-48

[41] Poologasundarampillai G, Ionescu C, Tsigkou O, Murugesan M, Hill RG, Stevens MM, Hanna JV, Smith ME, Jones JR (2010) Synthesis of bioactive class II poly[(gamma)-glutamic acid]/silica hybrids for bone regeneration. J Mater Chem 20(40):8952-8961

[42] Domingues RZ, Clark AE, Brennan AB (2001) A sol-gel derived bioactive fibrous mesh. J Biomed Mater Res 55(4):468-474
[43] Hatcher BM, Seegert CA, Brennan AB (2003) Polyvinylpyrrolidone modified bioactive glass fibers as tissue constructs: in vitro mesenchymal stem cell response. J Biomed Mater Res Part A 66(4):840-849

[44] Geltmeyer J, De Roo J, Van den Broeck F, Martins JC, De Buysser K, De Clerck K (2016) The influence of tetraethoxysilane sol preparation on the electrospinning of silica nanofibers. J Sol-gel Sci Technol 77(2):453-462

[45] Geltmeyer J, Van der Schueren L, Goethals F, De Buysser K, De Clerck K (2013) Optimum sol viscosity for stable electrospinning of silica nanofibres. J Sol-gel Sci Technol 67(1):188-195

[46] Poologasundarampillai G, Yu B, Jones JR, Kasuga T (2011) Electrospun silica/PLLA hybrid materials for skeletal regeneration. Soft Matter 7(21):10241-10251

[47] Toskas G, Cherif C, Hund R-D, Laourine E, Mahltig B, Fahmi A, Heinemann C, Hanke T (2013) Chitosan(PEO)/ silica hybrid nanofibers as a potential biomaterial for bone regeneration. Carbohydr Polym 94(2):713-722

[48] Song J-H, Yoon B-H, Kim H-E, Kim H-W (2008) Bioactive and degradable hybridized nanofibers of gelatin-siloxane for bone regeneration. J Biomed Mater Res Part A $84 \mathrm{~A}(4): 875-884$

[49] Gao C, Gao Q, Li Y, Rahaman MN, Teramoto A, Abe K (2013) In vitro evaluation of electrospun gelatin-bioactive glass hybrid scaffolds for bone regeneration. J Appl Polym Sci 127(4):2588-2599

[50] Kim HW, Song JH, Kim HE (2005) Nanofiber generation of gelatin-hydroxyapatite biomimetics for guided tissue regeneration. Adv Funct Mater 15(12):1988-1994

[51] Huang Z-M, Zhang YZ, Ramakrishna S, Lim CT (2004) Electrospinning and mechanical characterization of gelatin nanofibers. Polymer 45(15):5361-5368

[52] Ayres C, Bowlin GL, Henderson SC, Taylor L, Shultz J, Alexander J, Telemeco TA, Simpson DG (2006) Modulation of anisotropy in electrospun tissue-engineering scaffolds: analysis of fiber alignment by the fast fourier transform. Biomaterials 27(32):5524-5534

[53] Song J-H, Kim H-E, Kim H-W (2008) Production of electrospun gelatin nanofiber by water-based co-solvent approach. J Mater Sci Mater Med 19(1):95-102. doi:10. 1007/s10856-007-3169-4

[54] Erencia M, Cano F, Tornero JA, Fernandes MM, Tzanov T, Macanás J, Carrillo F (2015) Electrospinning of gelatin fibers using solutions with low acetic acid concentration: effect of solvent composition on both diameter of electrospun fibers and cytotoxicity. J Appl Polym Sci 132(25):42115. doi:10.1002/app.42115

[55] Zhang S, Huang Y, Yang X, Mei F, Ma Q, Chen G, Ryu S, Deng X (2009) Gelatin nanofibrous membrane fabricated by 
electrospinning of aqueous gelatin solution for guided tissue regeneration. J Biomed Mater Res Part A 90A(3):671-679

[56] Zha Z, Teng W, Markle V, Dai Z, Wu X (2012) Fabrication of gelatin nanofibrous scaffolds using ethanol/phosphate buffer saline as a benign solvent. Biopolymers 97(12):1026-1036

[57] Guo L, Colby RH, Lusignan CP, Whitesides TH (2003) Kinetics of triple helix formation in semidilute gelatin solutions. Macromolecules 36(26):9999-10008

[58] Bigi A, Panzavolta S, Rubini K (2004) Relationship between triple helix content and mechanical properties of gelatin films. Biomaterials 25(25):5675-5680

[59] Su LF, Miao L, Tanemura S, Xu G (2012) Low-cost and fast synthesis of nanoporous silica cryogels for thermal insulation applications. Sci Technol Adv Mater 13(3):035003

[60] Negahi Shirazi A, Fathi A, Suarez FG, Wang Y, Maitz PK, Dehghani F (2016) A novel strategy for softening gelatinbioactive-glass hybrids. ACS Appl Mater Interfaces 8(3):1676-1686

[61] Blaker JJ, Knowles JC, Day RM (2008) Novel fabrication techniques to produce microspheres by thermally induced phase separation for tissue engineering and drug delivery. Acta Biomater 4(2):264-272

[62] Brinker CJ (1988) Hydrolysis and condensation of silicates: effects on structure. J Non-cryst Solids 100(1):31-50

[63] Liu X, Smith LA, Hu J, Ma PX (2009) Biomimetic nanofibrous gelatin/apatite composite scaffolds for bone tissue engineering. Biomaterials 30(12):2252-2258

[64] Joly-Duhamel C, Hellio D, Djabourov M (2002) All gelatin networks: 1. Biodiversity and physical chemistry. Langmuir 18(19):7208-7217

[65] da Silva Parize DD, de Oliveira JE, Foschini MM, Marconcini JM, Mattoso LHC (2016) Poly(lactic acid) fibers obtained by solution blow spinning: effect of a greener solvent on the fiber diameter. J Appl Polym Sci 133(18):43379

[66] Oliveira JE, Moraes EA, Costa RGF, Afonso AS, Mattoso LHC, Orts WJ, Medeiros ES (2011) Nano and submicrometric fibers of poly(D, L-lactide) obtained by solution blow spinning: process and solution variables. J Appl Polym Sci 122(5):3396-3405

[67] da Silva Parize DD, Foschini MM, de Oliveira JE, Klamczynski AP, Glenn GM, Marconcini JM, Mattoso LHC (2016) Solution blow spinning: parameters optimization and effects on the properties of nanofibers from poly(lactic acid)/ dimethyl carbonate solutions. J Mater Sci 51(9):4627-4638. doi:10.1007/s10853-016-9778-x

[68] Mead-Hunter R, King AJC, Mullins BJ (2012) Plateau rayleigh instability simulation. Langmuir 28(17):6731-6735

[69] Oliveira JE, Mattoso LHC, Orts WJ, Medeiros ES (2013) Structural and morphological characterization of micro and nanofibers produced by electrospinning and solution blow spinning: a comparative study. Adv Mater Sci Eng 2013:1-14

[70] Liu Y-L, Su Y-H, Lai J-Y (2004) In situ crosslinking of chitosan and formation of chitosan-silica hybrid membranes with using $\gamma$-glycidoxypropyltrimethoxysilane as a crosslinking agent. Polymer 45(20):6831-6837

[71] Ren L, Tsuru K, Hayakawa S, Osaka A (2001) Synthesis and characterization of gelatin-siloxane hybrids derived through sol-gel procedure. J Sol-gel Sci Technol 21(1):115-121

[72] Tonda-Turo C, Gentile P, Saracino S, Chiono V, Nandagiri VK, Muzio G, Canuto RA, Ciardelli G (2011) Comparative analysis of gelatin scaffolds crosslinked by genipin and silane coupling agent. Int J Biol Macromol 49(4):700-706

[73] Gabrielli L, Russo L, Poveda A, Jones JR, Nicotra F, Jiménez-Barbero J, Cipolla L (2013) Epoxide opening versus silica condensation during sol-gel hybrid biomaterial synthesis. Chem Eur J 19(24):7856-7864

[74] Ren L, Tsuru K, Hayakawa S, Osaka A (2002) Novel approach to fabricate porous gelatin-siloxane hybrids for bone tissue engineering. Biomaterials 23(24):4765-4773

[75] Innocenzi P, Kidchob T, Yoko T (2005) Hybrid organicinorganic sol-gel materials based on epoxy-amine systems. J Sol-gel Sci Technol 35(3):225-235

[76] Carboni D, Pinna A, Malfatti L, Innocenzi P (2014) Smart tailoring of the surface chemistry in GPTMS hybrid organicinorganic films. New J Chem 38(4):1635-1640

[77] Dieudonne X, Montouillout V, Jallot E, Fayon F, Lao J (2014) Bioactive glass hybrids: a simple route towards the gelatin-SiO2-CaO system. J Chem Soc Chem Commun 50(63):8701-8704

[78] Lao J, Dieudonne X, Fayon F, Montouillout V, Jallot E (2016) Bioactive glass-gelatin hybrids: building scaffolds with enhanced calcium incorporation and controlled porosity for bone regeneration. J Mater Chem B 4(14):2486-2497

[79] McCann JT, Marquez M, Xia Y (2006) Highly porous fibers by electrospinning into a cryogenic liquid. J Am Chem Soc 128(5):1436-1437

[80] Lin S, Ionescu C, Baker S, Smith ME, Jones JR (2010) Characterisation of the inhomogeneity of sol-gel-derived $\mathrm{SiO} 2-\mathrm{CaO}$ bioactive glass and a strategy for its improvement. J Sol-gel Sci Technol 53(2):255-262

[81] Poologasundarampillai G, Yu B, Tsigkou O, Wang D, Romer F, Bhakhri V, Giuliani F, Stevens MM, McPhail DS, Smith ME, Hanna JV, Jones JR (2014) Poly( $\gamma$-glutamic acid)/silica hybrids with calcium incorporated in the silica network by use of a calcium alkoxide precursor. Chem Eur J 20(26):8149-8160 